\title{
Junctional ectopic tachycardia following tetralogy of fallot repair in children under 2 years
}

\author{
Mohamed Fouad Ismail ${ }^{1,2}$, Amr A. Arafat ${ }^{3}$, Tamer E. Hamouda ${ }^{1,4}$, Amira Esmat El Tantawy ${ }^{5}$, Azzahra Edrees ${ }^{1}$, \\ Abdulbadee Bogis ${ }^{1}$, Nashwa Badawy ${ }^{1,5}$, Alaa B. Mahmoud ${ }^{1,3}$, Ahmed Farid Elmahrouk ${ }^{1,3^{*}}$ (D) and Ahmed A. Jamjoom ${ }^{1}$
}

\begin{abstract}
Background: Junctional ectopic tachycardia is a serious arrhythmia that frequently occurs after tetralogy of Fallot repair. Arrhythmia prophylaxis is not feasible for all pediatric cardiac surgery patients and identification of high risk patients is required. The objectives of this study were to characterize patients with JET, identify its predictors and subsequent complications and the effect of various treatment strategies on the outcomes in selected TOF patients undergoing total repair before 2 years of age.
\end{abstract}

Methods: From 2003 to 2017, 609 patients had Tetralogy of Fallot repair, 322 were included in our study. We excluded patients above 2 years and patients with preoperative arrhythmia. 29.8\% of the patients $(n=96)$ had postoperative JET.

Results: JET patients were younger and had higher preoperative heart rate. Independent predictors of JET were younger age, higher preoperative heart rate, cyanotic spells, non-use of B-blockers and low Mg and Ca ( $p=0.011$, $0.018,0.024,0.001,0.004$ and 0.001 ; respectively). JET didn't affect the duration of mechanical ventilation nor hospital stay ( $p=0.12$ and 0.2 respectively) but prolonged the ICU stay $(p=0.011)$. JET resolved in $39.5 \%(n=38)$ of patients responding to conventional measures. Amiodarone was used in 31.25\% $(n=30)$ of patients and its use was associated with longer ICU stay $(p=0.017)$. Ventricular pacing was required in 4 patients (5.2\%). Median duration of JET was $30.5 \mathrm{~h}$ and 5 patients had recurrent JET episode. Timing of JET onset didn't affect ICU $(p=0.43)$ or hospital stay $(p=0.14)$ however, long duration of JET increased ICU and hospital stay ( $p=0.02$ and 0.009 ; respectively).

Conclusion: JET increases ICU stay after TOF repair. Preoperative B-blockers significantly reduced JET. Patients with preoperative risk factors could benefit from preoperative arrhythmia prophylaxis and aggressive management of postoperative electrolyte disturbance is essential.

Keywords: Congenital heart disease, Arrhythmia, Junctional ectopic tachycardia; tetralogy of Fallot

\section{Background}

Postoperative junctional ectopic tachycardia (JET) is a potential life-threatening arrhythmia occurring after congenital cardiac surgery. [1] The incidence of JET following congenital cardiac surgery varies widely in literature which can be attributed to the different diagnostic criteria and the great variability in the patients'

\footnotetext{
* Correspondence: A_marouky@hotmail.com;

Ahmed.elmahrouki1@med.tanta.edu.eg; Ael-Mahrouk@KFSHRC.edu.sa

${ }^{1}$ Cardiothoracic Surgery Department, King Faisal Specialist Hospital and Research Center, MBC J-16, P.O Box: 40047, Jeddah 21499, Saudi Arabia

${ }^{3}$ Cardiothoracic Surgery Department, Tanta University, Tanta, Egypt

Full list of author information is available at the end of the article
}

characteristics among the published studies. [2] Incidence of JET is higher when the intervention is close to the atrioventricular node and bundle of Hiss as in tetralogy of Fallot (TOF) and complete atrioventricular canal (AVC) repair. [1,3] Several treatment strategies ranging from pharmacologic agents to atrial cardiac pacing are used sequentially to lower the ventricular rate and re-establish atrioventricular synchrony. [4-6] Recently, the effect of several pharmacologic agents on reducing postoperative JET was evaluated. [7-9]

Generalization of preoperative prophylaxis for arrhythmia in all patients undergoing surgery for congenital heart

(c) The Author(s). 2018 Open Access This article is distributed under the terms of the Creative Commons Attribution 4.0 International License (http://creativecommons.org/licenses/by/4.0/), which permits unrestricted use, distribution, and reproduction in any medium, provided you give appropriate credit to the original author(s) and the source, provide a link to the Creative Commons license, and indicate if changes were made. The Creative Commons Public Domain Dedication waiver (http://creativecommons.org/publicdomain/zero/1.0/) applies to the data made available in this article, unless otherwise stated. 
defects is non-practical and preoperative identification of high risk patients is essential. Although many studies were concerned with postoperative arrhythmia, little have focused on JET following total TOF repair in infants. $[1,10]$ The objectives of this study were to characterize patients with JET, identify its predictors and subsequent complications and the effect of various treatment strategies on the outcomes in selected TOF patients undergoing total repair before 2 years of age.

\section{Methods}

\section{Study population}

This is a retrospective cohort study performed at King Faisal Specialized Hospital and Research Centre in Jeddah, Saudi Arabia. A total of 609 patients underwent surgical TOF repair between January 2003 and December 2017. We excluded patients older than 2 years $(n=$ 231) and patients with rhythm disturbances or heart block preoperative $(n=16)$. Moreover; patients with serious postoperative arrhythmia other than JET $(n=17)$ and patients with missing postoperative JET diagnosis criteria from the medical records $(n=23)$ were excluded. A total of 322 patients were included in the study. Approval of the institutional review board was obtained before data collection and the need for patients' consents was waived due to the retrospective nature of the study.

\section{Operative technique}

Surgical repair was performed by consultant level cardiac surgeons through median sternotomy. Bicaval cannulation was performed and cardioplegic arrest was done by antegrade cold crystalloid cardioplegia. Median temperature of the perfusate was $32{ }^{\circ} \mathrm{C}$. Right atrial incision was performed in $98 \%$ of the patients for resection of the RVOT obstructing bundles and closure of the ventricular septal defect and trans-annular patch (TAP) was used in $64 \%$ of the patients. Patients who required TAP were mainly operated upon during the early study period and our current strategy is to avoid TAP and preserve the pulmonary valve when possible. Pulmonary valvotomy was performed in 71 patients $(22.5 \%)$ and resection of the right ventricular outflow tract (RVOT) obstructing bundles was done in $94.7 \%(n=305)$. Concomitant tricuspid valve repair was performed in 55 patients (17.4\%).

\section{Data collection}

Patients' medical charts were retrospectively reviewed to collect preoperative variables including patients age at the time of surgery, gender, weight $(\mathrm{Kg})$, body surface area (BSA) (m2), preoperative B-blockers administration, associated cardiac anomalies and previous palliative surgical procedures as modified Blalock-Tausig Shunt. Preoperative 12 leads electrocardiogram were reviewed in all patients to identify the preoperative rhythm and PR interval, QRS duration were calculated. Preoperative heart rate was reported from the anesthesia records after sedating the patients. Intraoperative variables include cardiopulmonary bypass (CPB) time (minutes), aortic cross clamp time (minutes), temperature of the perfusate, use of transannular patch (TAP) and resection of right RVOT obstructing muscle bundle and the use of right atrial or right ventricular approach.

\section{Postoperative data}

We included all patients who had JET whatever its duration and the onset of JET whether intraoperatively or postoperatively in the intensive care unit (ICU) was determined. The criteria used for JET diagnosis were i) Heart rate $>175 \mathrm{Bpm}$ ii) Absent $\mathrm{P}$ wave from lead II of EKG iii) Narrow QRS complexes iv) Ventricular rate faster than atrial rate with AV dissociation.

Protocol of JET management included discontinuation of unnecessary inotropes, infusion of IV fluids boluses for hypovolemic patients with low central venous pressure, cooling (reducing temperature to $36-36.5{ }^{\circ} \mathrm{C}$ ), and sedation. At the same time postoperative electrolyte imbalance was aggressively corrected with $\mathrm{K}, \mathrm{Ca}$, and magnesium. Our Intensive care protocol is to maintain serum $\mathrm{K}>4.1 \mathrm{mmol} / \mathrm{L}$, ionized $\mathrm{Ca}>1.1 \mathrm{mmol} / \mathrm{L}$ and serum $\mathrm{Mg}>1.1 \mathrm{mg} / \mathrm{dL}$. During early study period, digoxin was administered at $5 \mu \mathrm{cg} / \mathrm{kg} /$ dose IV once to control the ventricular rate. Amiodarone was administered as a bolus with $5 \mathrm{mg} / \mathrm{kg}$ IV over one hour and if JET persisted, further infusion at $5 \mu \mathrm{cg} / \mathrm{kg} / \mathrm{min}$ was given till sinus rhythm was established or the heart rate slowed to an acceptable rate with stable hemodynamic. Our policy for possible postoperative pacing is to insert ventricular pacing wire unless the patient showed heart block immediately on recovery from $\mathrm{CPB}$, in this case we insert both atrial and ventricular pacing wires. Dopamine, dobutamine, milrinone, epinephrine administration was reported, and we calculated the inotropic score at the time of onset of arrhythmia using the following formula: $\{$ (dopamine + dobutamine $) \times 1\}+$ $($ milrinone X 20 $)+\{($ epinephrine + norepinephrine $) \times 100\}$.

\section{Study endpoints}

Preoperative, operative and postoperative variables were used to predict the occurrence of JET. The impact of JET on duration of mechanical ventilation (hours), ICU stay (days) and total duration of hospital stay (days) were analyzed.

\section{Statistical analysis \\ Data presentation}

Continuous variables were presented as mean \pm Standard deviation and categorical variables as number and percent. 


\section{Data analysis}

Mann-Whitney test was used to compare continuous variables and for categorical variables Chi2 was used or Fisher Exact test if the frequency is less than 5. Multiple imputation was used to handle the missing variables. Multivariable logistic regression models were used to identify the predictors of postoperative JET. Three models were constructed from the preoperative, operative and postoperative variables respectively and the variables in each model didn't exceed 9 variables to power the multivariable analysis. Odds ratio, $p$-value and 95\% confidence interval were reported. The effect of JET on the postoperative outcomes was assessed using propensity score analysis. The probability of having JET was calculated using multivariable logistic regression model after adjustment of the measured preoperative confounders. Propensity score was used in the adjusted model to predict the effect of JET on the postoperative outcomes. To fulfil the linearity assumptions of the model, non-normally distributed continuous variables were rescaled by, inverse squared and inverse transformations. $P$-value lesser than 0.05 was considered significant. All statistical analyses were performed using STATA 14 software (Statacorp, Texas- USA).

\section{Results}

A total of 322 patients had tetralogy of Fallot repair during the study period and met the inclusion criteria. Patients' age at time of operation ranged from 2 to 23 months and male to female ratio was 1.6: 1 . JET occurred in 96 patients (29.9\%) and patients were classified into JET and non-JET groups.

\section{Patients' characteristics}

Patients who had postoperative JET were significantly younger $(p=0.01)$ and had higher preoperative heart rate $(p=0.03)$. Associated lesions were Atrial Septal Defect ( $n$ $=6)$, complete AVC $(n=3)$, persistent Left Superior Vena Cava $(n=1)$, Patent Ductus Arteriosus $(n=7)$, Multiple Aorto- Pulmonary Collateral Arteries $(n=2)$, peripheral pulmonary artery stenosis $(n=3)$, pulmonary atresia $(n=$ 5) and 12 patients had prior modified Blalock Taussig shunt. There was no statistically significant difference in associated lesion between patients with and without postoperative JET $(p=0.8)$. Fifteen patients in JET group had preoperative B-blockers (19.5\%) versus 62 patients $(80.5 \%)$ in Non-JET group $(p=0.015)$. (Table 1$)$.

Operative variables are comparable between both groups with no statistically significant difference in the measured variables. Table 1 shows the comparison of the preoperative and operative variables. Postoperative inotropes administered before the onset of JET were compared between groups and showed no significant
Table 1 Comparison of the preoperative and operative data between JET and non-JET patients

\begin{tabular}{|c|c|c|c|}
\hline Variable & JET group $(n=96)$ & Non-JET $(n=226)$ & $P$ \\
\hline Male (n) & $56(58.3 \%)$ & $144(63.7 \%)$ & 0.36 \\
\hline Age (months) & $7.5 \pm 3$ & $8.35 \pm 2.99$ & 0.01 \\
\hline Weight (Kg) & $6.95 \pm 1.8$ & $7.37 \pm 2.1$ & 0.11 \\
\hline BSA (m2) & $0.36 \pm 0.07$ & $0.37 \pm 0.6$ & 0.42 \\
\hline Oxygen saturation (\%) & $82.4 \pm 7.7$ & $82.8 \pm 8$ & 0.14 \\
\hline Cyanotic spells (n) & $20(21.7 \%)$ & $42(19 \%)$ & 0.58 \\
\hline \multicolumn{4}{|l|}{ EKG } \\
\hline Heart Rate $(\mathrm{b} / \mathrm{m})$ & $103.7 \pm 13.5$ & $99.97 \pm 12.97$ & 0.03 \\
\hline P duration & $0.06 \pm 0.01$ & $0.06 \pm 0.01$ & 0.7 \\
\hline P-R interval & $0.13 \pm 0.02$ & $0.13 \pm 0.03$ & 0.7 \\
\hline QRS & $0.06 \pm 0.02$ & $0.06 \pm 0.01$ & 0.5 \\
\hline Pulmonary annulus (mm) & $6.36 \pm 2$ & $6.47 \pm 2.1$ & 0.57 \\
\hline RVOT gradient (mmHg) & $70.8 \pm 14.6$ & $71.5 \pm 15.1$ & 0.61 \\
\hline Cross-Clamp time (min) & $74.4 \pm 2.6 .5$ & $75.3 \pm 27.1$ & 0.77 \\
\hline $\begin{array}{l}\text { Cardiopulmonary } \\
\text { bypass (min) }\end{array}$ & $102.1 \pm 31.1$ & $101.3 \pm 32$ & 0.7 \\
\hline Temperature (Celsius) & $32 \pm 1.5$ & $31.7 \pm 1.5$ & 0.12 \\
\hline Tricuspid valve repair (n) & $13(13.5 \%)$ & $42(19 \%)$ & 0.24 \\
\hline Pulmonary valvotomy (n) & $25(26.6 \%)$ & $47(20.7 \%)$ & 0.25 \\
\hline RA approach (n) & 93 (96.9\%) & $223(98.7 \%)$ & 0.28 \\
\hline RVOT resection (n) & $91(94.8 \%)$ & $214(94.7 \%)$ & 0.97 \\
\hline Trans-annular patch (n) & 66 (68.75\%) & 141 (62.39\%) & 0.27 \\
\hline
\end{tabular}

Continuous variables are presented as mean \pm SD and categorical variables as number (\%)

$R A$ right atrial, $R V O T$ right ventricular outflow tract

difference in patients who received dopamine, dobutamine, epinephrine and milrinone between JET and non-JET patients. Levels of serum potassium, calcium and magnesium before the onset of JET were compared and showed significantly lower magnesium level in patients who developed JET $(p=0.001)$. (Table 2$)$.

\section{Factors associated with JET}

By multivariable analysis of the measured preoperative variables, younger age, cyanotic spells, non-use of B-blockers and higher preoperative heart rate predicted the postoperative JET ( $p=0.011,0.024,0.001$ and 0.018 ; respectively). By constructing a separate model for the operative variables, none of the measured operative variables predicted the postoperative JET. In the postoperative variables model; low magnesium and calcium independently predicted the occurrence of JET $(p=$ 0.004 and 0.001; respectively). (Table 3).

\section{Effect of JET}

Ventilation time didn't differ significantly between JET patients $(23.4 \pm 24.7 \mathrm{~h})$ vs non-JET patients $(19.5 \pm$ 
Table 2 Comparison of the inotropes and serum electrolytes in JET and non-JET groups

\begin{tabular}{llll}
\hline Variable & JET group $(n=96)$ & Non-JET $(n=226)$ & $P$ \\
\hline Inotropes & & & \\
Dopamine (n) & $22(23.4 \%)$ & $65(29.28 \%)$ & 0.28 \\
Dobutamine (n) & $47(49.5 \%)$ & $91(41 \%)$ & 0.16 \\
Epinephrine ( $\mathrm{n})$ & $34(36.6 \%)$ & $85(37.8 \%)$ & 0.84 \\
Milrinone $(\mathrm{n})$ & $47(50 \%)$ & $127(58.3 \%)$ & 0.18 \\
Inotrope score & $12.3 \pm 14$ & $9.2 \pm 6$ & 0.17 \\
Electrolytes & & & \\
PH & $7.36 \pm 0.066$ & $7.37 \pm 0.06$ & 0.16 \\
Potassium (mmol/L) & $3.98 \pm 0.45$ & $4.07 \pm 0.56$ & 0.17 \\
Magnesium (mEq/L) & $1.01 \pm 0.39$ & $1.14 \pm 0.43$ & 0.001 \\
Calcium (mmol/L) & $2.32 \pm 0.32$ & $2.24 \pm 0.35$ & 0.08
\end{tabular}

Continuous variables are presented as mean $\pm S D$ and categorical variables as number (\%)

$11.6 \mathrm{~h}, p=0.11)$. Patients with JET had longer ICU stay (6.1 \pm 5.8 vs $5 \pm 1.9$ days, $p=0.01)$ and longer hospital stay $(15.1 \pm 11.2$ vs $13.4 \pm 6.5$ days, $p=0.04)$. Propensity score matching was used to estimate the effect of JET on the duration of ventilation, ICU and hospital stay after adjustment of the measured preoperative variables. JET didn't affect the duration of mechanical ventilation nor hospital stay ( $p=0.12$ and 0.2 respectively) but significantly prolonged ICU stay $(p=0.011)$. (Table 4$)$ Hospital mortality occurred in 10 patients $(3.11 \%), 4$ patients with JET (4.1\%) versus 6 patients without JET (2.65\%) $(p=$ 0.49). (Table 4).

\section{Course of JET}

JET was diagnosed post cardiopulmonary bypass and inside the operation room in 30 patients $(30.25 \%)$ and in the ICU in 66 patients (68.75\%). Subgroup analysis was done to identify the difference between patients who had JET intraoperatively and those who had JET in the ICU. No difference between both groups as regard age $(p=$

Table 3 Predictors of postoperative JET

\begin{tabular}{llll}
\hline Variable & OR & $P$ & $95 \% \mathrm{Cl}$ \\
\hline Pre-operative & & & \\
Age & 0.86 & 0.011 & $0.76-0.97$ \\
Cyanotic spells & 2.9 & 0.024 & $1.15-7.41$ \\
B-blockers & 0.2 & 0.001 & $0.08-0.51$ \\
Preoperative HR & 1.02 & 0.018 & $1.004-1.04$ \\
Post-operative & & & \\
Mg & 0.37 & 0.004 & $0.19-0.7$ \\
Ca & 0.4 & 0.001 & $0.23-0.7$ \\
\hline
\end{tabular}

$O R$ odds ratio, $\mathrm{Cl}$ confidence interval
Table 4 Effect of JET on duration of mechanical ventilation, ICU and hospital stay

\begin{tabular}{llll}
\hline Variable & Coefficient & $\mathrm{P}$ & $95 \% \mathrm{Cl}$ \\
\hline Ventilation time $^{\mathrm{a}}$ & -1.5 & 0.123 & $-0.036-0.004$ \\
ICU stay $^{\mathrm{b}}$ & -0.3 & 0.011 & $-0.057--0.007$ \\
Hospital stay $^{\mathrm{a}}$ & -0.009 & 0.2 & $-.025-.007$ \\
\hline a $^{\text {anver }}$ & & &
\end{tabular}

inverse squared

${ }^{\text {inverse }}$

$0.17)$, gender $(p=0.82)$, body surface area $(p=0.89)$, preoperative heart rate $(p=0.86)$, preoperative oxygen saturation $(p=0.37)$, cyanotic spells $(p=0.86)$, B blockers $(p=0.65), \mathrm{CPB}$ time $(p=0.11)$ and ischemic time $(p=0.24)$. After adjustment of the preoperative variables, no difference was found in duration of JET $(p=0.91)$, ICU stay $(p=0.43)$, ventilation time $(p=0.52)$ and hospital stay (0.14) between both groups.

JET resolved in $39.5 \%(n=38)$ of patients responding to conventional measures. At the same time, postoperative electrolyte imbalance was aggressively corrected with $\mathrm{K}, \mathrm{Ca}$, and $\mathrm{Mg}$. Fifty-nine patients (61.5\%) received digoxin and digoxin administration was not significantly associated with the duration of mechanical ventilation $(p=0.77)$, ICU stay $(p=0.43)$ nor hospital stay $(p=$ $0.98)$ in patients with JET. Amiodarone was used in $31.25 \%(n=30)$ of patients and no relation was found between the use of amiodarone and the duration of mechanical ventilation $(p=0.07)$ nor hospital stay $(p=$ $0.35)$. However, amiodarone use was significantly associated with longer ICU stay $(p=0.017)$. Betablockers were used in 58 patients $(64.2 \%)$ with no significant association with the duration of mechanical ventilation $(p=$ $0.8)$, ICU $(p=0.37)$ or hospital stay $(p=0.07)$. Ventricular pacing was required in 4 patients $(4.16 \%)$ because of progression into heart block. Five patients (5.2\%) had a second episode of JET, 3 of them were males. Their median age was 7 months (ranged from 6 to 15 months) and median oxygen saturation was $80 \%$ (ranged from 79 to $85 \%$ ). None of these patients had preoperative B-blockers, 3 of them had TAP and JET occurred intraoperatively in 3 patients. Full recovery occurred in 4 patients and 1 patients progressed to complete heart block and required permanent pace maker.

The median duration of JET was $30.5 \mathrm{~h}$ and ranged from 3 to $96 \mathrm{~h}$. Longer duration of postoperative JET "i.e. above the median value" was significantly associated with lower preoperative oxygen saturation $(\mathrm{p}=0.01)$. After adjustment of the pre- JET variables, longer duration of JET was significantly associated with prolonged ICU $(p=0.02)$ and hospital stay $(p=0.009)$ but had no significant association with the duration of mechanical ventilation $(p=0.21)$ compared with patients with short JET duration. 


\section{Discussion}

Prophylaxis of arrhythmia after pediatric cardiac surgery became the focus of many trials recently. $[7,8,11,12]$ Generalization of prophylaxis in all patients undergoing surgery for congenital heart disease is difficult and may increase the hazard of surgery. In literature, various factors were found associated with the genesis of JET after surgical repair of congenital heart disease. Most of these studies [1, 10, 13-15] were performed in a wide variety of congenital heart defects. Including all types of congenital heart defects in risk models to predict postoperative JET underpowers the results as the incidence of JET varies widely in different congenital heart diseases and procedures. Based on several reports, JET is commonly associated with TOF $[1,10]$ therefore we included in our series TOF patients who underwent corrective surgery before 2 years of age. In our series the incidence of JET was $29.8 \%$ and this high incidence of JET can be explained by our strict selection criteria of those high-risk patients. The incidence of JET following TOF repair varied in the published series and ranged from 4 to $37 \%$. [8, 16-18] The great variability in JET incidence could be attributed to the diagnostic criteria used and the wide variability in patients' characteristics especially age. [2] Another explanation for this variability is the low patients number, it is remarkable that lower incidence of JET post TOF repair was documented with less number of TOF patients included in the study. Moreover, we included all patients who expressed JET whether were hemodynamically stable or not. In our study; younger age was significantly associated with increased risk of postoperative JET and this finding is consistent with other studies [14]. Younger patients are generally sicker and smaller hearts are more prone to damage by surgical technique and retraction. Increased preoperative heart rate predicted postoperative JET. Normal range of heart rate depends on patients' age and the definition of tachycardia is not consistent. In order to have a standardized condition for all patients, we reported the operation room heart rate after the patients were properly sedated. This also could explain the insignificant findings of the preoperative ECG measurements as usually they are not taken under standardized conditions and patients conditions during ECG recording significantly affected these ECG intervals.

Preoperative B-blockers were associated with significant reduction of postoperative JET in our patients which is consistent with a previous report. [19] Further randomized studies are required to evaluate Bblockers as a preoperative prophylaxis against JET in those high-risk patients.

Trans-atrial approach is our standardized approach for closure of ventricular septal defect and relief of RVOT obstruction and $98 \%$ of our patients were operated through RA. Although RA approach in a study of 343 patients independently predicted postoperative JET in the total patient series, no correlation was made with their 114 subsets of TOF patients. [20] Our surgical strategies have been shifted from the use of TAP to preservation of the pulmonary valve if possible as it has a proved efficacy in reducing the incidence of postoperative pulmonary regurgitation. [21] Nevertheless, TAP was not associated with JET in our series. Some authors documented a significant association between JET and prolonged ischemic and cardiopulmonary bypass time and higher bypass temperature [17, 22-24]. In our study, none of the operative variables predicted the postoperative JET. Cardiopulmonary bypass time affected JET in studies which included all congenital heart disease patients. In those patients, $\mathrm{CPB}$ time differed significantly between different lesions due to the different surgical procedure specific to each lesion Inotropes didn't predict JET in our patients. In contrary to this, dopamine or inotropic score were risk factors for JET in other series. $[14,17]$ Revision of electrolyte profiles in the sample just prior to JET occurrence proved that JET group had statistically significant lower serum magnesium and Calcium. Serum magnesium carries a lot of debate among authors, some documented its significance as a risk factor or as prophylactic therapy for JET, [25-27] others documented that magnesium and calcium levels were not significantly different between the two groups. [22]

Our experience in management of JET is to imply conventional strategies as correction of reduced intravascular volume, reduce body temperature, titrate inotropes to off if not affecting hemodynamic status of patients and aggressively correct electrolyte imbalance. In the early period of our study we used digoxin before the administration of amiodarone. Some authors [14] didn't recommend the use of digoxin in JET because its direct action of increasing excitability of all forms of myocardium, however, it was used to delay atrioventricular node bundle conduction maintaining a reasonable ventricular rate and to counteract the negative inotropic effect of Class III antiarrhythmic (sotalol and amiodarone). Recently amiodarone has gained popularity in JET treatment or prophylaxis. [5, 8] Many authors stated that class III antiarrhythmic drugs (sotalol and amiodarone) when given orally or intravenous, were shown to be almost devoid of negative inotropic effects [14, 18], however amiodarone use was associated with prolonged ICU stay in our JET patients.

In our series the median duration of JET was $30.5 \mathrm{~h}$ and many cases resolved smoothly without any hemodynamic instability with recurrence of a second episode of JET in $5.2 \%$ of the patients. Complications in the form of heart block requiring pacemaker insertion was encountered in 4 patients of the JET group. 
Junctional ectopic tachycardia significantly increased ICU stay but not the duration of the mechanical ventilation of hospital stay. This is explained by the benign course of our JET patients and the additional treatment required lead to increased ICU stay while there was no effect on total hospital stay. No difference in patients' characteristics or the outcome of JET in patients who had JET onset intraoperatively versus those who had JET onset in the ICU. This can be explained by the overlap of the time frame between both groups and it is recommended for future to classify JET into early and late onset based on time of onset rather than the place of onset. Moreover, the duration of JET had an impact on the patients' outcome since longer JET episodes lead to prolonged ICU and hospital stay which is expected due to the increase in time required for treating those patients compared with shorter JET episodes.

In summary, JET post tetralogy of Fallot repair can be predicted based on the preoperative variables. Preoperative cyanotic spells were associated with postoperative JET and preoperative B-blockers significantly reduced postoperative JET. Postoperative electrolytes imbalance played a role in JET pathogenesis. JET had a benign course and didn't increase hospital mortality but it prolonged ICU stay. The outcome of JET was affected by the duration of JET episode but not the time of onset.

\section{Study strength and limitations}

The major limitation of the study is the retrospective design with its inherited biases. However, this is an acceptable design for rare outcomes. Many of the limitations of previously published reports were managed in our study including limiting selection to a specific age and pathology in contrast to other studies which included all types of congenital heart disease and wide range of age. The relatively large number in our series and the high incidence of JET in this subset of patients properly powered the multivariable analysis. Missing of some variables is another limitation however missing values didn't exceed $8 \%(1-7.1 \%)$ in the variables used in the analysis and multiple imputation is a suitable method to handle these missing variables. Recent studies [7, 9] showed that Dexmedetomidine has a role as a prophylactic and therapeutic agent for postoperative JET, however we didn't use it in our patients which could be another limitation of the study.

\section{Conclusion}

Junctional ectopic tachycardia is a frequent complication after Tetralogy of Fallot repair. It has a benign course; however, it prolongs ICU stay after TOF repair. Preoperative B-blockers reduced postoperative JET and patients with preoperative risk factors could benefit from preoperative arrhythmia prophylaxis. JET can be prevented by aggressive management of postoperative electrolyte disturbance. The outcome of JET was not affected by time of JET onset however, prolonged duration of JET had a negative impact of ICU and hospital stay.

\begin{abstract}
Abbreviations
BSA: Body surface area; CPB: Cardiopulmonary bypass; ICU: Intensive care unit; JET: Junctional Ectopic Tachycardia; RVOT: Right ventricular outflow tract; TAP: Trans-annular patch; TOF: Tetralogy of Fallot
\end{abstract}

\section{Funding}

This research received no specific grant from any funding agency in the public, commercial, or not-for-profit sectors.

Availability of data and materials

Data are available on request to the corresponding author.

\section{Authors' contributions}

IM Conducted the literature search analysis and interpretation of data, AA, Conducted the statistical analysis and interpretation of data, $\mathrm{HT}$ : Conducted the literature search, EAE: Designed the study, IA, Data Collection, BA, Data Collection, $\mathrm{NB}$, conducted the literature search, MAB, Analysis and interpretation of data, EA, Involved in the study design, and drafted the manuscript "corresponding author", $J A$, Supervised the study and conducted the review of data. All authors read and approved the final manuscript.

\section{Ethics approval and consent to participate}

The study was approved by the Institutional Review Board Committee of King Faisal Specialist hospital and research center Jeddah, Saudi Arabia. The need for informed consent was waived due to the retrospective nature of the study.

\section{Competing interests}

The authors declare that they have no competing interests.

\section{Publisher's Note}

Springer Nature remains neutral with regard to jurisdictional claims in published maps and institutional affiliations.

\section{Author details}

${ }^{1}$ Cardiothoracic Surgery Department, King Faisal Specialist Hospital and Research Center, MBC J-16, P.O Box: 40047, Jeddah 21499, Saudi Arabia.

${ }^{2}$ Cardio-thoracic Surgery Department, Mansoura University, Mansoura, Egypt.

${ }^{3}$ Cardiothoracic Surgery Department, Tanta University, Tanta, Egypt.

${ }^{4}$ Cardio-thoracic Surgery Department, Benha University, Benha, Egypt. ${ }^{5}$ The

Department of Pediatrics, Faculty of Medicine Cairo University, Cairo, Egypt.

Received: 16 March 2018 Accepted: 31 May 2018

Published online: 05 June 2018

\section{References}

1. Sahu MK, Das A, Siddharth B, Talwar S, Singh SP, Abraham A, et al. Arrhythmias in children in early postoperative period after cardiac surgery. World J Pediat Congenit Heart Surg. 2018;9(1):38-46.

2. Entenmann A, Michel M, Egender F, Hessling V, Kramer HH. Impact of different diagnostic criteria on the reported prevalence of junctional ectopic tachycardia after pediatric cardiac surgery. Pediatric Crit Care Med. 2016; 17(9):845-51.

3. Ozyilmaz I, Ergul Y, Ozyilmaz S, Guzeltas A. Junctional ectopic tachycardia in late period after early postoperative complete atrioventricular block: messenger of return to normal sinus rhythm? : Explanation with four case series. J Electrocardiol. 2017;50(3):378-82.

4. Imamura T, Tanaka Y, Ninomiya Y, Yoshinaga M. Combination of flecainide and propranolol for congenital junctional ectopic tachycardia. Pediat Int. 2015:57(4):716-8. 
5. Kovacikova L, Hakacova N, Dobos D, Skrak P, Zahorec M. Amiodarone as a first-line therapy for postoperative junctional ectopic tachycardia. Ann Thorac Surg. 2009;88(2):616-22.

6. Saiki H, Nakagawa R, Ishido H, Masutani S, Senzaki H. Landiolol hydrochloride infusion for treatment of junctional ectopic tachycardia in post-operative paediatric patients with congenital heart defect. Europace. 2013;15(9):1298-303

7. El Amrousy DM, Elshmaa NS, El-Kashlan M, Hassan S, Elsanosy M, Hablas N, et al. Efficacy of prophylactic Dexmedetomidine in preventing postoperative junctional ectopic tachycardia after pediatric cardiac surgery. J Am Heart Assoc. 2017;6:e004780. https://doi.org/10.1161/JAHA.116.004780.

8. Imamura M, Dossey AM, Garcia X, Shinkawa T, Jaquiss RD. Prophylactic amiodarone reduces junctional ectopic tachycardia after tetralogy of Fallot repair. J Thorac Cardiovasc Surg. 2012;143(1):152-6.

9. Kadam SV, Tailor KB, Kulkarni S, Mohanty SR, Joshi PV, Rao SG. Effect of dexmeditomidine on postoperative junctional ectopic tachycardia after complete surgical repair of tetralogy of Fallot: a prospective randomized controlled study. Ann Card Anaesth. 2015;18(3):323-8.

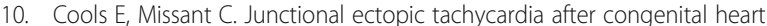
surgery. Acta Anaesthesiol Belg. 2014;65(1):1-8.

11. El-Shmaa NS, El Amrousy D, El Feky W. The efficacy of pre-emptive dexmedetomidine versus amiodarone in preventing postoperative junctional ectopic tachycardia in pediatric cardiac surgery. Ann Card Anaesth. 2016;19(4):614-20

12. Rajput RS, Das S, Makhija N, Airan B. Efficacy of dexmedetomidine for the control of junctional ectopic tachycardia after repair of tetralogy of Fallot. Ann Pediat Cardiol. 2014;7(3):167-72.

13. Andreasen JB, Johnsen SP, Ravn HB. Junctional ectopic tachycardia after surgery for congenital heart disease in children. Intensive Care Med. 2008;34(5):895-902.

14. Batra AS, Chun DS, Johnson TR, Maldonado EM, Kashyap BA, Maiers J, et al. A prospective analysis of the incidence and risk factors associated with junctional ectopic tachycardia following surgery for congenital heart disease. Pediatr Cardiol. 2006;27(1):51-5.

15. Talwar S, Patel K, Juneja R, Choudhary SK, Airan B. Early postoperative arrhythmias after pediatric cardiac surgery. Asian Cardiovasc Thorac Ann 2015;23(7):795-801.

16. Dodge-Khatami A, Miller OI, Anderson RH, Gil-Jaurena JM, Goldman AP, de Leval MR. Impact of junctional ectopic tachycardia on postoperative morbidity following repair of congenital heart defects. Eur J Cardiothorac Surg. 2002;21(2):255-9.

17. Hoffman TM, Bush DM, Wernovsky G, Cohen MI, Wieand TS, Gaynor JW, et al. Postoperative junctional ectopic tachycardia in children: incidence, risk factors, and treatment. Ann Thorac Surg. 2002;74(5):1607-11.

18. Pfammatter JP, Bachmann DC, Wagner BP, Pavlovic M, Berdat P, Carrel T, et al. Early postoperative arrhythmias after open-heart procedures in children with congenital heart disease. Pediatr Crit Care Med. 2001;2(3):217-22.

19. Mahmoud AB, Tantawy AE, Kouatli AA, Baslaim GM. Propranolol: a new indication for an old drug in preventing postoperative junctional ectopic tachycardia after surgical repair of tetralogy of Fallot. Interact Cardiovasc Thorac Surg. 2008;7(2):184-7.

20. Dodge-Khatami A, Miller OI, Anderson RH, Goldman AP, Gil-Jaurena JM, Elliott MJ, et al. Surgical substrates of postoperative junctional ectopic tachycardia in congenital heart defects. J Thorac Cardiovasc Surg. 2002; 123(4):624-30.

21. Arafat AA, Elatafy EE, Elshedoudy S, Zalat M, Abdallah N, Elmahrouk A. Surgical strategies protecting against right ventricular dilatation following tetralogy of Fallot repair. J Cardiothorac Surg. 2018;13(1):14.

22. Delaney JW, Moltedo JM, Dziura JD, Kopf GS, Snyder CS. Early postoperative arrhythmias after pediatric cardiac surgery. J Thorac Cardiovasc Surg. 2006; 131(6):1296-300

23. Valsangiacomo E, Schmid ER, Schupbach RW, Schmidlin D, Molinari L, Waldvogel K, et al. Early postoperative arrhythmias after cardiac operation in children. Ann Thorac Surg. 2002;74(3):792-6.

24. Abdelaziz O, Deraz S. Anticipation and management of junctional ectopic tachycardia in postoperative cardiac surgery: single center experience with high incidence. Ann Pediat Cardiol. 2014;7(1):19-24.

25. Dorman BH, Sade RM, Burnette JS, Wiles HB, Pinosky ML, Reeves ST, et al. Magnesium supplementation in the prevention of arrhythmias in pediatric patients undergoing surgery for congenital heart defects. Am Heart J. 2000; 139(3):522-8.
26. He D, Sznycer-Taub N, Cheng Y, McCarter R, Jonas RA, Hanumanthaiah S, et al. Magnesium lowers the incidence of postoperative junctional ectopic tachycardia in congenital heart surgical patients: is there a relationship to surgical procedure complexity? Pediatr Cardiol. 2015;36(6):1179-85.

27. Manrique AM, Arroyo M, Lin Y, El Khoudary SR, Colvin E, Lichtenstein S, et al. Magnesium supplementation during cardiopulmonary bypass to prevent junctional ectopic tachycardia after pediatric cardiac surgery: a randomized controlled study. J Thorac Cardiovasc Surg. 2010;139(1):162-9.e2.

\section{Ready to submit your research? Choose BMC and benefit from:}

- fast, convenient online submission

- thorough peer review by experienced researchers in your field

- rapid publication on acceptance

- support for research data, including large and complex data types

- gold Open Access which fosters wider collaboration and increased citations

- maximum visibility for your research: over $100 \mathrm{M}$ website views per year

At BMC, research is always in progress.

Learn more biomedcentral.com/submissions 